$$
\text { 정 수 진·권 용 진·박 민 찬 }
$$

\title{
A Case of Sacroiliitis Diagnosed with Positron-Emission Tomography with Normal Magnetic Resonance Imaging Finding
}

\author{
Soo-Jin Chung, Yong-Jin Kwon, Min-Chan Park \\ Division of Rheumatology, Department of Internal Medicine, \\ Yonsei University College of Medicine, Seoul, Korea
}

\section{증 례}

환 자: 30 미

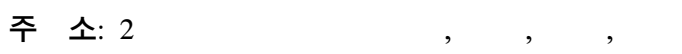

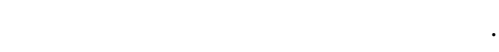

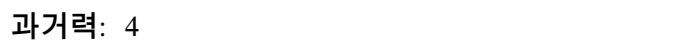

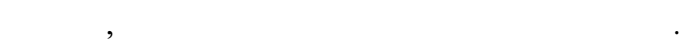

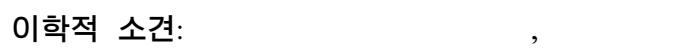

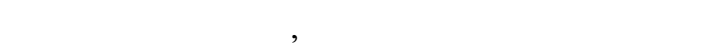

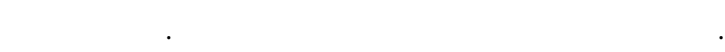

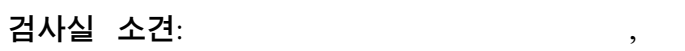

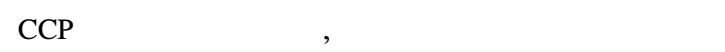

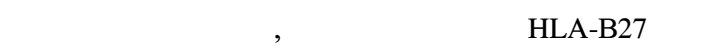

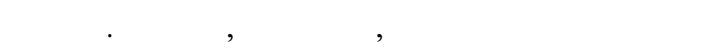

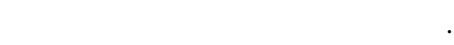

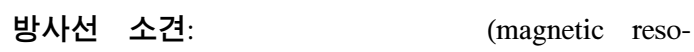

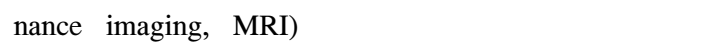

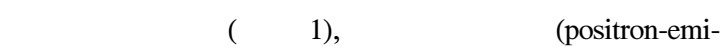

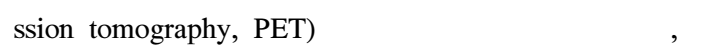

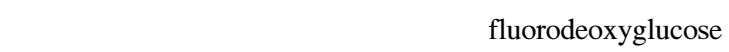

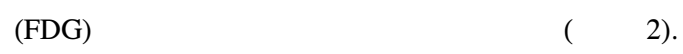

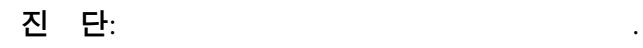

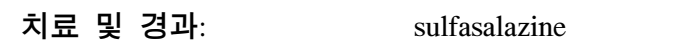

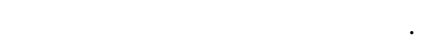

\section{고 찰}

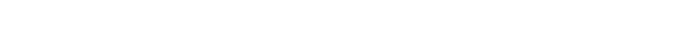

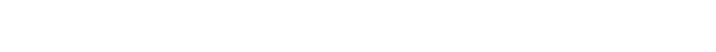

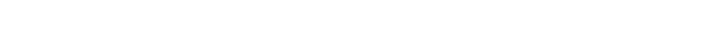

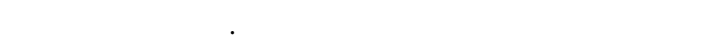

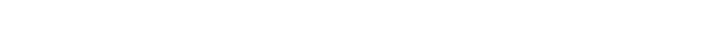

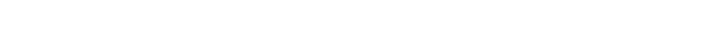

\footnotetext{
<접수일 : 2009년 12월 28일, 수정일 : 2010년 6월 11일, 심사통과일 : 2010년 6월 13일> ※통신저자 : 박 민 찬 


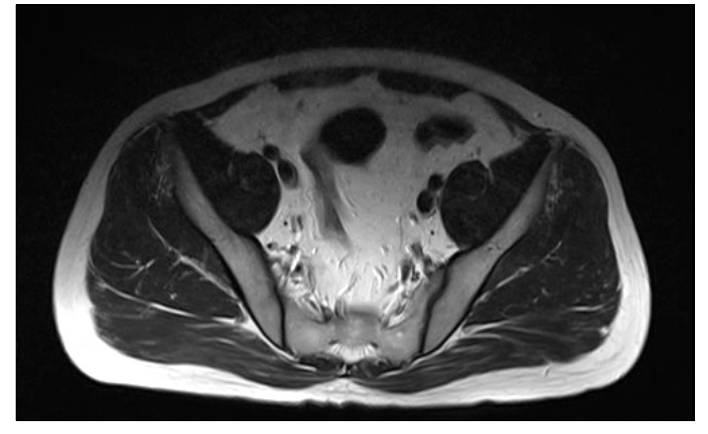

Fig. 1. T2-weighted transverse scan. Sacroiliac joints are grossly normal without pathologic change.

\section{참고문헌}

1) Ovadia D, Metser U, Lievshitz G, Yaniv M, Wientroub

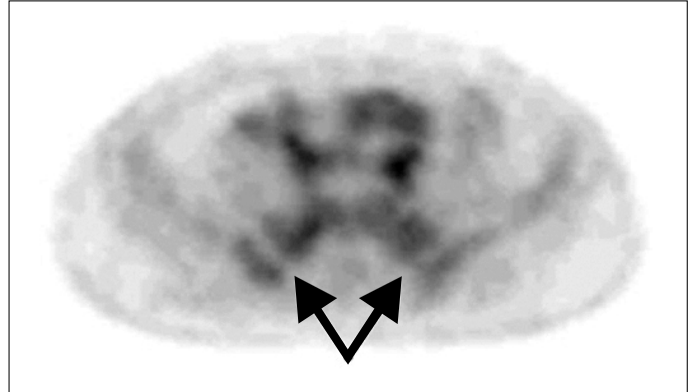

Fig. 2. Mild to moderate degree of increased FDG accumulation along the articular surface of bilateral sacroiliac joints.

S, Even-Sapir E. Back pain in adolescents: assessment with integrated 18F-fluoride positron-emission tomographycomputed tomography. J Pediatr Orthop 2007;27:90-3.

2) Akdeniz O, Alayli G, Tosun FC, Diren B, Cengiz K, Selcuk MB, et al. Early spondyloarthropathy: scintigraphic, biological, and clinical findings in MRI-positive patients. Clin Rheumatol 2008;27:469-74.

3) Heuft-Dorenbosch L, Landewe R, Weijers R, Wanders A, Houben $\mathrm{H}$, van der Linden $\mathrm{S}$, et al. Combining information obtained from magnetic resonance imaging and conventional radiographs to detect sacroiliitis in patients with recent onset inflammatory back pain. Ann Rheum Dis 2006;65:804-8.

4) Puhakka KB, Melsen F, Jurik AG, Boel LW, Vesterby A, Egund N. MR imaging of the normal sacroiliac joint with correlation to histology. Skeletal Radiol 2004;33: $1-15$. 